\title{
Prevalence of low back pain, seeking medical care, and lost time due to low back pain among manual material handling workers in the United States
}

Sue A. Ferguson ${ }^{1 *}$ (D), Andrew Merryweather², Matthew S. Thiese², Kurt T. Hegmann², Ming-Lun Lu³, Jay M. Kapellusch ${ }^{4}$ and William S. Marras ${ }^{1}$

\begin{abstract}
Background: Low back pain (LBP) is a common and costly problem throughout the United States. To achieve a greater understanding of the occupational risk factors, the National Institute for Occupational Safety and Health (NIOSH) funded a low back health effects consortium, which performed several surveillance studies throughout the United States. This study combines data from the consortium research groups resulting in a data set with nearly 2000 workers in various regions of the country. The purpose of this paper is to examine prevalence and personal risk factors of low back health effects among these workers.
\end{abstract}

Methods: There were three common questions regarding history of low back health effects in the past 12 months including 1) have you had LBP lasting 7 days, 2) have you sought medical care for LBP, and 3) have you taken time off work due to LBP. The questionnaire included demographic questions. There were five data collections institutions or sites including $\mathrm{NIOSH}$, Ohio State University, University of Wisconsin-Milwaukee, Texas A\&M University, and University of Utah.

Results: The 12-month period prevalence of low back pain lasting 7 days, seeking medical care, and lost time due to LBP were 25, 14 and 10\%, respectively. There were no statistically significant differences in gender, age or weight between cases and non-cases for any prevalence measure. The height of workers was significantly greater in the cases compared to non-cases for all three prevalence definitions. There were significant differences among the sites on the prevalence of seeking medical care for LBP and lost time due to LBP. The Ohio State University had significantly higher prevalence rates for seeking medical care and lost time due to LBP than University of Wisconsin, University of Utah, or Texas A\&M University.

Conclusion: LBP, the least severe low back health effect studied, had the highest prevalence (25\%) and lost time due to LBP, the most severe low back health effect studied, had the lowest prevalence (10\%) among nearly 2000 US manual material handling workers. There was a significant site or regional influence in prevalence rates for seeking medical care and lost time due to LBP.

Keywords: Low back pain, Prevalence, Seeking medical care, Lost time

\footnotetext{
* Correspondence: ferguson.4@osu.edu

${ }^{1}$ Spine Research Institute, The Ohio State University, 210 Baker Systems, 1971

Neil Avenue, Columbus, $\mathrm{OH}$ 43210, USA

Full list of author information is available at the end of the article
}

(c) The Author(s). 2019 Open Access This article is distributed under the terms of the Creative Commons Attribution 4.0 International License (http://creativecommons.org/licenses/by/4.0/), which permits unrestricted use, distribution, and reproduction in any medium, provided you give appropriate credit to the original author(s) and the source, provide a link to the Creative Commons license, and indicate if changes were made. The Creative Commons Public Domain Dedication waiver (http://creativecommons.org/publicdomain/zero/1.0/) applies to the data made available in this article, unless otherwise stated. 


\section{Background}

Low back pain is a leading cause of disability worldwide [1]. There are several surveillance measures that have been used in the literature to investigate prevalence rates and risk factors for low back health effects including presence of LBP of any severity, LBP that resulted in the seeking of medical care, and LBP resulting in lost time from work. Reported LBP prevalence rates range from $4 \%[2]$ to $69 \%[3,4]$ and vary depending on the length of time evaluated (e.g., lifetime, 1-month and point prevalence [5] as well as pain intensity [6]). LBP resulting in seeking medical care has reported prevalence rates ranging from $4.5 \%$ [7] to $32 \%$ [8] and has been shown to be influenced by the length of time of symptoms [9], gender [10] and race/ethnicity [10]. Taking time off from work, or lost time, is the least commonly used surveillance measure for low back health effects in the literature [11] and has prevalence rates between $4.6 \%$ [12] to $18 \%$ [13, 14]. These surveillance measures for low back health may represent a series of cascading events that start with mild LBP, which perhaps leads to an individual seeking medical care for LBP, possibly progressing to taking time off work for LBP that may recur any number of times and culminate with disabling LBP [15]. It is theorized that evaluating these three surveillance measures in a large population may provide further insight into the progression and potential prevention of LBP leading to disability.

A few studies have examined prevalence rates among workers using surveillance measures of LBP, seeking medical care for LBP and lost work time due to LBP. Ozgular et al. [6] examined prevalence of LBP in 725 active workers (office, hospital, warehouse, and airport registration of luggage) using LBP lasting at least 1 day, LBP with health care professional visit(s), and LBP with the taking of sick leave. The results showed a 1 day prevalence of $43 \%$, seeking medical care prevalence rate of $22 \%$, and LBP with sick leave of 9\% [6]. Merlino et al. [16] examined musculoskeletal disorders among 996 apprentice construction workers and found that in the past 12 months the prevalence for LBP symptoms was $54 \%$, seeking medical care prevalence was $17 \%$, and missed work prevalence was $7 \%$. Feng et al. [17] evaluated a group of 244 Taiwanese nurses and nursing staff and reported $66 \%$ prevalence of LBP lasting at least 1 day, $38 \%$ seeking medical care for LBP, and $11 \%$ with sick leave for LBP in the past 12 months. Abolfotouh et al. [13] examined several low back prevalence measures among a population of 254 nurses in Doha, Qatar. The 12 month period prevalence for LBP lasting at least 1 day was 54\%, prevalence for seeking treatment due to LBP was 34\%, and sick leave or lost time for LBP prevalence was 18\% [13].

Thus, there is a wide range of prevalence rates for low back health effects. These prevalence rates may be influenced by the length of time as well as the severity of low back health effect definition investigated, i.e. LBP, seeking medical care for LBP or lost work time for LBP. There is a lack of studies examining the prevalence of low back health effects using multiple definitions in a large occupational population in the United States. The objective of this study was two-fold 1) to combine data from several studies and examine the differences in prevalence of LBP, seeking medical care for LBP, and lost time due to LBP among a large population of US manual material handling workers and 2) to examine differences among personal risk factors for each prevalence measure.

\section{Methods/design}

This was a cross-sectional study design that combined data from several epidemiological studies that examined work related low back health. It is hypothesized that there will be differences in the prevalence rates among the three definitions of LBP furthermore this will result in differences among personal risk factors for the prevalence measures. The LBP research consortium included 5 members: 1) National institute of Occupational Safety and Health (NIOSH) 2) Ohio State University (OSU), 3) University of Wisconsin-Milwaukee (UWM), 4) Texas A\&M University (TAMU), and 5) University of Utah (UU). The individual consortium study findings have been previously published [5, 18-20]. All studies were approved by the respective institutional review boards (IRBs). The University of Wisconsin IRB had oversite for the merging of anonymized datasets.

Convenience samples of workers were enrolled from six US states: Illinois, Michigan, Ohio, Texas, Utah and Wisconsin. The NIOSH data was collected at a large dryer manufacturing facility in the state of Ohio. The OSU team collected data in 20 distribution centers in Ohio and 1 office furniture distribution center in Michigan. The 20 distribution centers were in one of four categories including automotive parts, grocery, apparel and general merchandise. The UU data was collected in the state of Utah in a variety of manufacturing facilities including medical products, apparel, cabinetry, salt and auto parts manufacturers as well as an alcohol distribution center and printing operations. The TAMU group collected data primarily at meat packing and grocery warehouse facilities and one upholstery facility in the state of Texas. The UWM data was collected in 15 facilities in the state of Wisconsin and one facility in the state of Illinois, and consisted of manufacturing and distribution facilities including automotive, apparel, window and door, food and beverage, household items, pharmaceutical and general merchandise. At all sites the inclusion criterion was the manual material handling job at the facility that the workers performed. Workers on a 
job of interest were recruited by a research team member. Researchers encouraged all workers on the job of interest to participate regardless of health issues. The exclusion criterion was working at the facility on a job without manual material handling tasks of interest. All workers signed a human subject's consent form prior to participating in the study. All data was collected at the respective work facilities resulting in a variety of occupational study settings. Participating employees received their regular wages during the study. All workers participating in the study received questionnaires that included demographic information (e.g., age, gender, race/ethnicity, height, weight) and cigarette usage. The questionnaires also included questions about low back health effects due to participants' jobs. Table 1 lists the specific questions regarding low back health effects.

The merged database had three categories of variables including 1) health effects and personal risk factors, 2) psychosocial exposure and 3) physical exposure measures. This analysis was only on prevalence of low back health effects and personal risk factors. Only subjects with complete baseline data for health effects and personal factors were eligible for prevalence analysis. Data analyses were initiated for the seeking of medical care question by dichotomization into either seeking medical care or not seeking medical care. Similarly, the missed work question was dichotomized into either no missed workdays or missed workdays. Statistical analyses were performed using SAS version 9.2. Descriptive statistics were calculated for the number of cases for each low back health effect definition and demographic information. To test for differences in the prevalence rates among the three outcome measures McNemar's Tests were performed. For continuous measures of age, weight, and height, T-tests were run for each case definition. To examine risk factor differences among the three prevalence measures general linear models (proc GLM) were utilized. Test statements were employed to evaluate differences due to consortium study site, gender, race/ ethnicity, and site by race/ethnicity interaction. Post hoc Ryan-Einot-Gabriel-Welsch REGWQ multiple range

Table 1 Research questions utilized to measure low back health effects

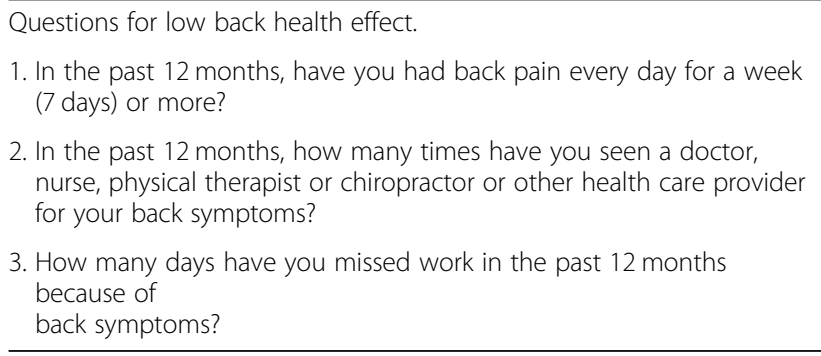

tests were used to determine significant differences among the sites and race/ethnicity.

\section{Results}

The combined total sample from all the consortium sites was 1976 workers and, of those, 1929 completed the minimum baseline data requirements for inclusion in the prevalence analysis. Table 2 lists total population, cases, and prevalence for the three measures of low back health effects. Prevalence rates for LBP lasting at least 1 week, seeking medical care, and lost time due to LBP were 25,14 , and $10 \%$, respectively. McNemar's test statistics for LBP lasting 1 week vs. seeking medical care was 211.5 and $p$-value $<0.0001$. Prevalence of low back pain lasting at least 1 week vs. lost time due to LBP was a McNemar's test statistic of 242.5 and p-value $<0.001$. Finally the McNemar's test statistic for seeking medical care vs. lost time due to LBP was 31.1 and $p$-value < 0.0001 . Thus, the null hypothesis that the distributions are the same was rejected and therefore, each prevalence definition resulted in a significantly different prevalence rate for the same 1 year period.

Seventy-five percent of the participants were male. The average age, weight, and height of the study population are listed in Table 3. The race/ethnicity of the 1929 workers was 1253 (65\%) white, 275 (14\%) Hispanic/Latino, 269 (14\%) black/African American, 52 (3\%) Asian, 47 (2\%) Native Hawaiian or Pacific Islanders, and $3(<1 \%)$ Native American or Native Alaskan and 30 (2\%) declined to respond or were other. Nearly half of the $1929(n=956$, $49 \%$ ) of the workers had never smoked.

Table 3 lists the means and standard deviations for age, weight, and height for cases and non-cases for each definition of low back health effect and indicators for significant differences. There was no difference in age or weight between cases and non-cases. Worker stature was significantly different between the cases and the non-cases for all three prevalence measures. Workers with low back health effects were approximately $2.0 \mathrm{~cm}$ taller than the workers without.

The general linear model test statement results indicated no significant differences for gender or race for any of the low back health effect prevalence measures. The test statement evaluating differences among the sites varied as a function of the definition of low back health effect. The prevalence measure of LBP lasting at least 1 week showed no statistically significant differences among the sites (data not shown). Conversely, the seeking medical care for LBP prevalence measure showed significant differences among the sites $(p<0.001)$. Figure 1 illustrates the 12-month period prevalence among the different sites. The different letters above the bars in the chart indicate statistically significant differences among the sites from the post hoc REGWQ test results. The OSU site had a significantly 
Table 2 Cases and prevalence as a function of low back health effect definition

\begin{tabular}{llll}
\hline & \multicolumn{2}{l}{ Low Back Health Effect Definition } & \\
\cline { 2 - 4 } & Low Back Pain lasting at least one week & Seeking Medical Care for LBP & Lost Work Time for LBP \\
\hline Cases & 483 & 272 & 192 \\
Population of Workers & 1929 & 1927 & 1929 \\
Prevalence & $25 \%$ & $14 \%$ & $10 \%$ \\
\hline
\end{tabular}

greater 12-month period prevalence rate at slightly over $25 \%$ than all other sites, as indicated in Fig. 1 by the letter A above the bar. NIOSH had a statistically significant lower 12-month period prevalence of seeking medical care compared to OSU (indicated by the letter B in Fig. 1 above the bar) and a significantly greater 12-month period prevalence in LBP with seeking medical care compared to UWM, UU, and TAMU. There was no difference in seeking medical care 12-month period prevalence among UWM, UU, and TAMU, as indicated in Fig. 1 by the letter $\mathrm{C}$ above the bars for the three sites.

The general linear model also showed a statistically significant difference among the sites for lost time due to LBP $(p<0.05)$. Figure 2 illustrates the differences in lost time due to LBP prevalence among the sites. The letters above the bars indicate statistical differences from the post hoc REGWQ test results. The OSU data had the highest 12 -month period prevalence at approximately $16 \%$ for lost time due to LBP. There was no significant difference between OSU and NIOSH at $12 \%$ in lost time as indicated with the letter A above both bars, but OSU had significantly higher lost time 12-month period prevalence than the other three sites. Figure 2 illustrates with the letter B above both bars that there was no significant difference between NIOSH and TAMU at 6\% lost time prevalence.

Table 3 T-test results for continuous demographic measures means (standard deviation) between cases and non-cases by low back health effect definition

\begin{tabular}{|c|c|c|c|}
\hline & Age (years) & Weight (kg) & Height $(\mathrm{cm})$ \\
\hline Total Sample & $36.2(11.6)$ & $84.8(20.9)$ & $173.2(10.2)$ \\
\hline \multicolumn{4}{|c|}{ Low Back Pain $\geq 7$ days } \\
\hline Cases & $36.6(11.7)$ & $85.2(19.5)$ & $174.5(9.6)$ \\
\hline Non Cases & $36.1(11.5)$ & $84.6(21.4)$ & $172.7(10.4)$ \\
\hline$p$-values & 0.4031 & 0.4840 & $0.0004^{*}$ \\
\hline \multicolumn{4}{|c|}{ Seeking Medical Care for LBP } \\
\hline Cases & $35.8(10.9)$ & $85.6(19.0)$ & $175.5(9.4)$ \\
\hline Non Cases & $36.3(11.6)$ & $84.6(21.2)$ & $172.7(10.4)$ \\
\hline$p$-values & 0.5586 & 0.4715 & $0.0001^{*}$ \\
\hline \multicolumn{4}{|c|}{ Lost Work Time for LBP } \\
\hline Cases & $35.0(10.9)$ & $85.3(19.0)$ & $175.0(9.1)$ \\
\hline Non Cases & $36.4(11.6)$ & $84.7(21.1)$ & $173.0(10.4)$ \\
\hline$p$-values & 0.1191 & 0.7409 & $0.0039^{*}$ \\
\hline
\end{tabular}

Note: ${ }^{*}$ indicates statistical significance
Finally, there was no significant difference in lost time prevalence among UWM, UU, and TAMU, as shown in Fig. 2 with the letter $C$ above all three sites.

\section{Discussion}

The principal finding of this research was that prevalence rates of low back health effects in the past 12 month period varied dramatically as a function of the three definitions in a large population of US workers. The prevalence rates for LBP lasting at least 1 week, seeking medical care, and lost time due to LBP were 25, 14 and $10 \%$, respectively. McNemar's test showed that each of the three prevalence rates were statistically significantly different from one another. Worker stature was the only personal risk factor that was significantly different between cases and non-cases among the three prevalence measures, and that average difference was small (i.e., cases approximately $2 \mathrm{~cm}$ taller than non-cases).

One of the strengths of the current study was the nearly 2000 workers that participated from six US states. This is the largest study of its kind that evaluated multiple definitions of low back health effects. Examining the prevalence rates with respect to the theory of cascading events [15], LBP the earliest surveillance measure studied had the highest prevalence, progressing next to medical visits there was a decrease in prevalence and finally to lost time due to LBP which had the lowest prevalence and presumed to be the most advanced or severe low back health effect in the progression. Thus, as surveillance measures for low back health effects progress in severity the prevalence rates decrease. Examining risk factors for each of these surveillance measures may provide insights into the prevention of chronic disabling LBP.

The pattern of period prevalence rates in the current study may be compared to other studies that examined all three prevalence measures. The current study and the literature $[6,13,16,17]$ all similarly reported that LBP had the highest prevalence rate, that there was a decrease in the prevalence rates in all the studies for seeking medical care, and that the lowest prevalence rate was for lost time due to LBP. Interestingly, two sites in this current study, UU and TAMU, had higher prevalence for lost time due to LBP than seeking medical care for LBP, which 


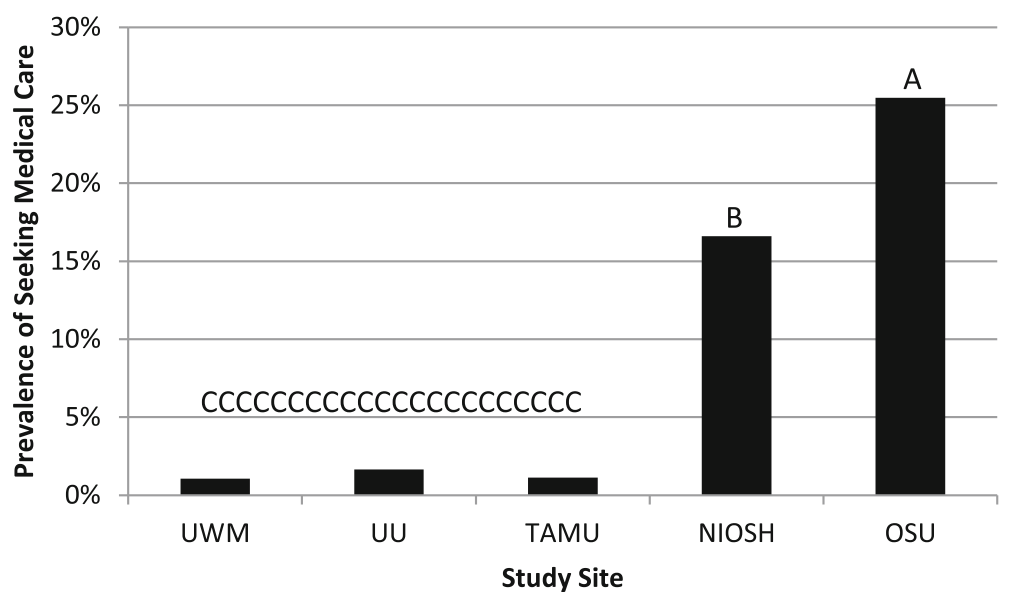

Fig. 1 Prevalence of seeking medical care for LBP in the past 12 months as a function of the study site. The bars with different letters above them are statistically significantly difference from one another. Note: UWM = University of Wisconsin, UU = University of Utah, TAMU- Texas A\&M University, NIOSH = National Institute of Occupational Safety and Health, OSU = Ohio State University

contradicts the literature and the aforementioned theory of progression. These differences may be due to a combination of workers compensation insurance differences and/or cultural differences in seeking medical care for workplace injuries. The UU and TAMU pattern may also be due to factors not studied. One possible explanation for the lack of seeking care in Utah and Texas may be the lack of available health care providers in the region. Combs et al. [21] reported that the ratio of primary care physician to population, which is how primary care physician availability has been evaluated, was 63.4 in the state of Utah in 2008, which was the lowest among all 50 states. Gong et al. [22] found Texas to be one of the states with a severe physician shortage between 1999 and 2004. The
American Association of Medical Colleges in 2007 ranked all 50 states from highest to lowest on the ratio of physician to population, Texas and Utah were among the bottom 10 states on the ratio [23]. Thus it was thought the low prevalence for seeking medical care in the UU and TAMU data may be due to the lack of availability of physicians in the regions where those data were collected. Alternatively, there may be sufficient physicians in the region for healthcare needs and instead some cultural differences not captured by ethnicity or other questions that promote self-care instead of seeking care from a medical provider in the Utah and Texas regions, which may result in lower prevalence for seeking care compared to lost time due to LBP. Regardless, the overall trend in

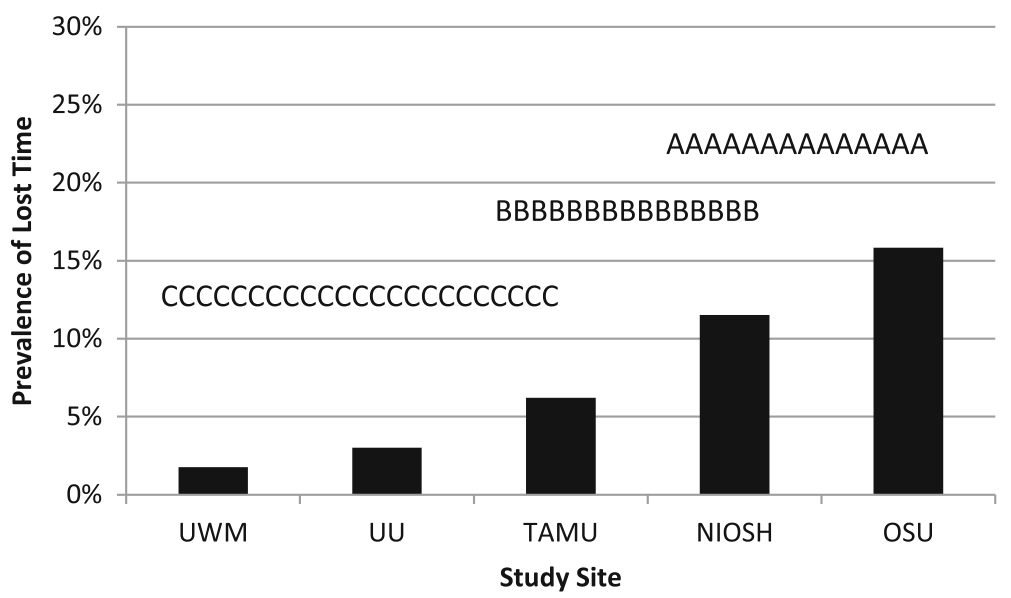

Fig. 2 Prevalence of lost time for low back pain in the past 12 months as a function of the study site. The bars with different letters above them are statistically significantly difference from one another. Note: UWM = University of Wisconsin, UU = University of Utah, TAMU- Texas A\&M University, $\mathrm{NIOSH}=$ National Institute of Occupational Safety and Health, OSU = Ohio State University 
the current study followed the pattern established in the literature, which illustrates the strength of having a large and diverse sample.

The 12-month period prevalence rate of LBP lasting 7 days or more in the current study was $25 \%$. Both Abolfotough [13] and Feng [17] reported prevalence rates much higher than the current study. It is hypothesized that the higher prevalence in the literature are due to the one-day duration of symptoms compared to the 7 -day duration with the current study. This hypothesis is supported by Ozgular et al. [6], which reported a 1 day LBP prevalence of $43 \%$ as well as a prevalence rate of $17 \%$ for LBP lasting 30 days. Thus, for the shorter duration of pain symptoms the prevalence rate was higher than the current study and for the longer 30 day duration of symptoms the prevalence was lower than the current study.

In the current study, the seeking medical care for LBP definition had a 12-month period prevalence of $14 \%$. This prevalence rate is low in comparison to the literature, which ranges from 17 to $38 \%$. In the report ranking the ratio of physician to population [23] by state, Ohio and Michigan are at the average with 236.6 physicians per 100,000 population and rank 17 and 18, respectively. The state of Illinois ranks 21, Wisconsin ranks 24. Thus none of the participating states in the current study rank particularly high on the physician to population ratio scale. This may be one explanation for why the seeking care prevalence was lower in the current study compared to the literature. The Merlino study was completed in the United States with $17 \%$ prevalence. The Merlino et al. [16] was collected in Iowa, Illinois, Oregon and Washington, which rank 41, 21, 13 and 16, respectively on the number of physicians per 100,000 in population in 2007. It may be that the increased availability in physicians in Oregon and Washington resulted in an increased prevalence in the Merlino study compared to the current study since both studies examined manual material handling workers. The higher prevalence rates for seeking medical of 38\% [17] and 34\% [13] may also be due to the population studied. It is hypothesized that nurses or health care providers may be more likely to seek medical care for LBP than those who perform manual material handling tasks.

Our analyses indicate that there were significant differences among the sites for seeking medical care. In a study of the American population seeking medical care for various illnesses, it was found that race/ethnicity significantly influenced seeking care for LBP [10]. The current study did not show a statistically significant difference in seeking medical care due to race/ethnicity nor was there an interaction between the sites and race. In a study examining ICD-9 codes for pain, the United States was divided into 4 regions including south, west, north central and northeast [24]. The two ICD-9 codes that were most comparable to the current study were LBP and degenerative disc disease codes. Interestingly, there were significant differences in prevalence in each of these ICD-9 codes among the different regions of the country. Different sites in the current study collected data from different states. The seeking medical care for LBP measure had higher 12-month period prevalence rates in Ohio and Michigan compared to Illinois, Wisconsin, Utah and Texas. The regions defined by Murphy et al. [24] do not match up exactly to the states in the current study however the common finding between the two studies is a statistically significant difference in 12-month period prevalence for seeking medical care as a function of the state or region within the United States.

The third 12-months prevalence measure was lost time and is thought to indicate the most severe level of low back health effect quantified. Overall, the current study had a lost time prevalence of $10 \%$. Ozgular et al. [6] had a prevalence rate of $9 \%$ for sick leave or lost time, which was very close to the current study. Merlino et al. [16] reported a lost time 12-month period prevalence rate of $7 \%$, which was slightly lower than the current study. Feng et al. [17] found a sick leave 12 -month period prevalence of $10 \%$, the same as the current study. Abolfotuoh et al. [13] reported a 12 -month period prevalence of $18 \%$ for lost time, which was slightly higher than the current study. Given the differences in the populations studied, the job exposures and the variability in the LBP prevalence among these studies it is remarkable that the lost time prevalence among these studies is this comparable. Figure 3 illustrates the consistency in the prevalence of lost time among the different studies with various populations and across different cultures, suggesting that this may be a stable surveillance measure for study of low back health effects. Davis and Kotowski [11] in a review of musculoskeletal disorders among nurses found that prevalence of self-reported lost time was the least investigated low back health surveillance measure. Given the stability of the self-reported lost time surveillance measure in the literature, future research may want to focus on self-reported lost time instead of pain surveillance measures. It should be noted that this was a measure of self-reported lost time away from work and not disability. In some cases, disability has been measured via a subjective questionnaire to quantify impairment of activities of daily living and not a measure of work disability [25]. Self-reported lost time from work may provide an effective and consistent surveillance measure that eliminates some of the confounding factors that may influence subjective disability and pain measures. 


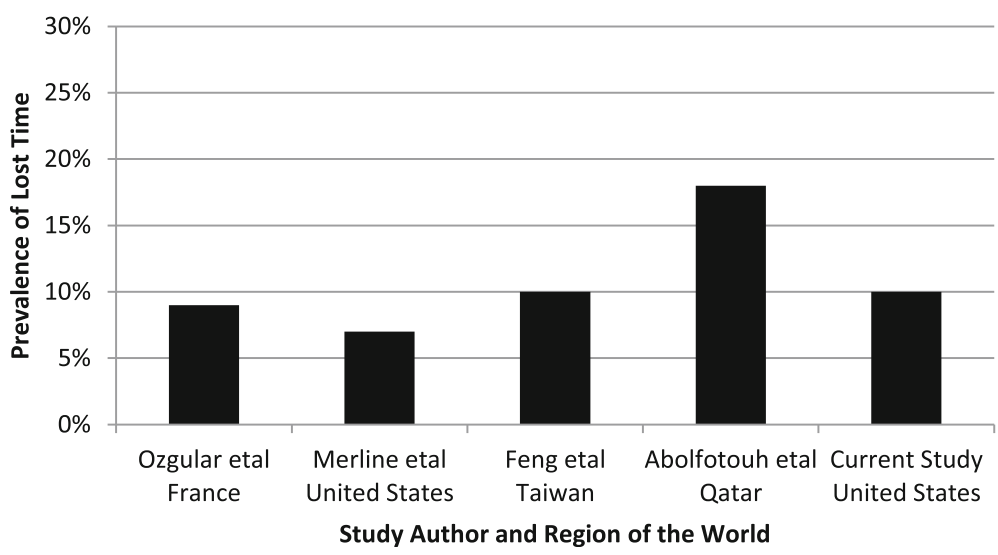

Fig. 3 Prevalence of lost time as a function of study author and region of the world where data was collected

Examining the 12-month period prevalence of LBP lasting at least 1 week, seeking medical care for LBP, and lost time due to LBP may provide a mechanism to quantify low back health effects that suggests evidence of a possible progressive disease leading to disability, as theorized by Ferguson and Marras [15]. With this theory, the least severe measure would be LBP of any duration, and would more likely be studied through population-based questionnaire data. Interestingly, prevalence of LBP may be as low as $4 \%$ for chronic LBP [2] and as high as $69 \%$ for 1 day LBP in Malaysian railroad workers [4]. Seeking medical care for LBP prevalence rates ranged from $4.5 \%$ [7] to $32 \%$ [8] and lost time, the most severe measure of LBP prevalence rates, ranged from $4.6 \%$ [12] to $18 \%$ [13]. Thus, the more severe the definition of low back health effect used, the smaller the range and average prevalence in the literature. If LBP is a progressive disease process, then by examining the exposure-response relationships between the risk factors and each low back health effect measure we may develop a greater understanding of the interactions of physical, psychosocial and psychological components at each stage of the process and potentially reduce the risk of the progression. More research that examines the progression of LBP measures in individuals across a spectrum of low back health effects would enhance our understanding of whether, and to what extent, there is a progression of LBP leading to disability. In addition, research into the progression latency of the LBP measures may help management and insurance companies plan strategies for reducing incidences and costs of LBP.

\section{Limitations}

There are several limitations in this study. First, it only examined 12 month period prevalence of LBP lasting 7 days, seeking medical care due to LBP, and lost work time due to LBP and the difference among the definitions may not be related to causal pathways. Second, this study had all manufacturing and distribution center jobs and therefore the results may not be applicable to other workplace settings. Third, the study population was predominantly male therefore the study results may not extrapolate to majority female populations. Finally, this paper examined only a portion of a large data set, the inclusion of physical job demands and workplace psychosocial factors in future analyses may help control some of the potential confounding effects of regional differences on various measures of low back health outcomes.

\section{Conclusions}

The 12 month period prevalence for low back pain lasting at least 1 week, medical care due to LBP and lost work time due to LBP was 25,14 and $10 \%$, respectively. There were significant differences in period prevalence rates among the sites or regions of the United State for seeking medical care as well as lost time due to LBP.

\section{Abbreviations}

LBP: Low Back Pain; NIOSH: National institute of Occupational Safety and Health; OSU: Ohio State University; TAMU: Texas A\&M University; UU: University of Utah; UWM: University of Wisconsin-Milwaukee

\section{Acknowledgements}

The findings and conclusions in this study are those of the authors and do not necessarily represent the views of the National Institute for Occupational Safety and Health.

We would like to acknowledge our friend and colleague Dr. Arun Garg, who recently past away, for his leadership, guidance and support on this project. He was also one of the pioneers in the field of occupational ergonomics and worked tirelessly to improve workplace safety for several decades.

\section{Funding}

This study was funded by the National Institute for Occupational Safety and Health grant \#RO1OH010916 "Exposure-response relationship for low back pain from pooled data". The funding body did not have a role in the design of the study, analysis or interpretation of the data. The manuscript was reviewed by NIOSH reviewers prior to submission to the journal.

Availability of data and materials

The dataset used for analysis during the current study are available from the corresponding author on reasonable request. 


\section{Authors' contributions}

SAF, AM, MST, KTH, ML, JMK, and WSM had a critical role in the design or acquisition of initial studies, combining or analyzing the larger data set, drafting or critically revising the article. All authors read and approved the final manuscript and revisions.

\section{Ethics approval and consent to participate}

The combined data research protocol was approved by the Internal Review Board of the University of Wisconsin. The protocol was approved exempt number 15.312. All participants signed consent at the time of the original data collection.

\section{Consent for publication}

Not applicable.

\section{Competing interests}

The authors declare that they have no competing interests.

\section{Publisher's Note}

Springer Nature remains neutral with regard to jurisdictional claims in published maps and institutional affiliations.

\begin{abstract}
Author details
${ }^{1}$ Spine Research Institute, The Ohio State University, 210 Baker Systems, 1971 Neil Avenue, Columbus, OH 43210, USA. ${ }^{2}$ Rocky Mountain Center for Occupational \& Environmental Health, Department of Family and Preventive Medicine, University of Utah, 391 Chipeta Way, Suite C, Salt Lake City, UT 84108 , USA. ${ }^{3}$ National Institute for Occupational Safety and Health, Taft Laboratories, 1090 Tusculum Ave. MS C-24, Cincinnati, OH 45226, USA. ${ }^{4}$ Occupational Science \& Technology, University of Wisconsin-Milwaukee, P.O. Box 413, Milwaukee, WI 53201, USA.
\end{abstract}

Received: 8 June 2018 Accepted: 26 April 2019

Published online: 22 May 2019

\section{References}

1. Hoy D, March L, Brooks P, Blyth F, Woolf A, Bain C, Williams G, Smith E, Vos $T$, Barendregt J, Murray C, et al. The global burden of low back pain: estimates from the global burden of disease 2010 study. Ann Rheum Dis. 2014;73:968-74 D.

2. Freburger JK, Holmes GM, Agans RP, Jackson A, Darter J, Wallace A, Castel L, Kalsbeek W, Carey T. The rising prevalence of chronic low back pain. Arch Intern Med. 2009;169:251-8.

3. Deyo RA, Mirza SK, Martin BI. Back pain prevalence and visit rates estimates from U.S. national survey, 2002. Spine. 2006;31:2724-7.

4. Ganasegeran K, Perianayagam W, Nagaraj P. Al-Dubai S. Psycho-behavioural risk of low back pain in railway workers. Occup Med. 2014;64:372-275.

5. Thiese MS, Hegman KT, Wood EM, Garg A, Moore JS, Kapellusch JM, Forster J, Green T, Stoddard G, Biggs J. Low-back pain ratings for lifetime, 1-month period, and point prevalence in a large occupational population. Hum Factors. 2014;56:86-97.

6. Ozgular A, Leclerc A, Landre M, Pietri-Taleb F, Niedhammer I. Individual and occupational determinants of low back pain according to various definitions of low back pain. J Epidemiol Community Health. 2000;54:215-20.

7. Plenet A, Gourmelen J, Chastang JF, Ozgular A, Lanoe JL, Leclerc A. Seeking care for lower back pain in the French population aged 30 to 69: the results of the 2002-2003 Decennale Sante survey. Ann Phys Rehabil Med. 2010;43:224-38.

8. Garg A, Kapellusch J, Hegmann K, Moore JS, Boda S, Bhoyar P, Thiese MS, Merryweather A, Deckow-Schaefer G, et al. The NIOSH lifting equation and low-back pain, part 2. Association with seeking care in the backworks prospective cohort study. Hum Factors. 2014;56:44-57.

9. Eisenberg DM, Davis RB, Ettner SL, Appel S, Wilkey S, Rompay MV, Kessler RC. Trends in alternative medicine use in the United States, 1990-1997. JAMA. 1998;280:1569-75

10. St. Sauver JL, Warner DO, Yawn BP, Jacobson DJ, ME MG, Pankratz JJ, Melton $L$, Roger JL, WA EJOR. Why do patients visit their doctors? Assessing the most prevalent conditions in a defined US population. Mayo Clin Proc. 2013;88:56-67.
11. Davis K, Kotowski S. Prevalence of musculoskeletal disorders for nurses in hospitals, long-term care facilities, and home health care: a comprehensive review. Hum Factors. 2015;57:754-92.

12. Guo HR, Tanaka S, Halperin WE, Cameron LL. Back pain prevalence in US industry and estimates of lost workdays. Am J Public Health. 1999;89:1029-35.

13. Abolfotouh S, Mahmoud K, Faraj K, Moammer G, ElSayed A, Abolfotouh MA. Prevalence, consequences and predictors of low back pain among nurses in a tertiary care setting. Int Orthop. 2015;39:2439-49.

14. Gilkey D, Enebo B, Keefe T, Vela Acosta M, Hautaluoma J, Bigelow P, Rosecrance J, Herron R. Low back pain in Hispanic residential carpenters. J Chiropr Med. 2007:6:2-14.

15. Ferguson SA, Marras WS. A literature review of low back disorder surveillance measures and risk factors. Clin Biomech. 1997;12:211-26.

16. Merlino L, Rosecrance J, Anton D, Cook T. Symptoms of musculoskeletal disorder among apprentice construction workers. Appl Occup Environ Hyg. 2003;18:57-64.

17. Feng $\mathrm{C}$, Chen $\mathrm{M}, \mathrm{Mao}$ I. Prevalence of and risk factors for different measures of low back pain among female nursing aides in Taiwanese nursing homes. BMC Musculoskelet Disord. 2007:8:52.

18. Marras WS, Lavender SA, Ferguson SA, Splittstoesser RE, Yang G. Quantitative dynamic measures of physical exposure predict low back functional impairment. Spine. 2010:35:914-23.

19. Garg A, Boda S, Hegman KT, Moore JS, Kapellusch JM, Bhoyar P, Thiese MS, Merryweather A, Deckow-Schaefer G, Bloswick D, et al. The NIOSH lifting equation and low back pain, part 1. Association with low back pain and the backworks prospective cohort study Special Issue: Epidemiology studies of workplace musculoskeletal disorders. Human Factors. 2014;56:6-28.

20. Lu M, Waters T, Krieg E, Werren D. Efficacy of the revised NIOSH lifting equation for predicting risk of low back pain associated with manual lifting: a one-year prospective study. Hum Factors. 2014;56:73-85.

21. Coombs J, Morgan P, Pedersen D, Koduri S, Alder S. Factors associated with physician assistant practice in rural and primary care in Utah. Int J Family Med. 2011. https://doi.org/10.1155/2011/879036.

22. Gong G, Braddock E, Zhang Y, Hudson C, Lefforge D, O'Bryant S. Trend and racial disparities in infant mortality rate in Texas from 1990 to 2004. J Natl Med Assoc. 2009;101:1149-53.

23. American association of medical colleges. 2007 State Physician Workforce Data Book. Center for Workforce Studies. 2007; Dec.

24. Murphy K, Han J, Yang S, Hussaini SMQ, Elsamadicy AA, Parente B, Xie J, Pagadala P, Lad S. Prevalence of specific types of pain diagnoses in a sample of United States adults. Pain Physician. 2017;20:e257-68.

25. Chiwaridzo M, Naidoo N. Functional consequences and health-care seeking behavior for recurrent non-specific low back pain in Zimbabwean adolescents: a cross-sectional study. Euro Spine J. 2016;25:643-50.

Ready to submit your research? Choose BMC and benefit from:

- fast, convenient online submission

- thorough peer review by experienced researchers in your field

- rapid publication on acceptance

- support for research data, including large and complex data types

- gold Open Access which fosters wider collaboration and increased citations

- maximum visibility for your research: over $100 \mathrm{M}$ website views per year

At BMC, research is always in progress.

Learn more biomedcentral.com/submissions 